\title{
Large vessel disease in children with chronic kidney disease
}

\author{
*Vaishnavi Venkatachari Iyengar ${ }^{1}$, Shakuntala Sanjay Prabhu ${ }^{1}$, Sumitra Venkatesh ${ }^{1}$, Uma Sankari Ali ${ }^{1}$
}

Sri Lanka Journal of Child Health, 2019; 48(2): 127-133

\begin{abstract}
Objectives: To assess early atherosclerotic changes using echocardiography and to correlate with the clinical and biochemical parameters associated with chronic kidney disease (CKD).
\end{abstract}

Method A cross sectional study was carried out in a tertiary care hospital over a period of 2 years. All 45 children with CKD registered with the nephrology unit were assessed and 43 without congenital cardiac disease were included. Data regarding onset of $\mathrm{CKD}$, stage of $\mathrm{CKD}$, biochemical profile and carotid intima-media thickness (CIMT) measured by B-mode echocardiography were analysed in these children. Correlation of CIMT with the stage of CKD, biochemical and clinical parameters associated with CKD was the main outcome measured.

Results: Ninety percent of the patients had high CIMT. The mean CIMT was more in children with end stage renal disease (ESRD) $(0.139 \pm 0.009 \mathrm{~cm}$ vs $0.112 \pm 0.007 \mathrm{~cm} ; p=0.003)$. There was a significant difference between the mean CIMT in normotensive patients $(0.104 \pm 0.008 \mathrm{~cm})$ and well controlled systolic and diastolic hypertension $[(0.134 \pm 0.009 \mathrm{~cm}) \quad$ and $\quad(0.132 \pm 0.009 \mathrm{~cm})$ respectively]. Mean CIMT in children with uncontrolled systolic and diastolic hypertension group $(0.152 \pm 0.009 \mathrm{~cm})$ was higher as compared to the mean CIMT in patients well controlled hypertension and normotensive patients $(0.116 \pm 0.006 \mathrm{~cm} ; p=0.0214)$.

Conclusions: CIMT is an echocardiographic marker for cardiovascular disease in CKD. Hypertension is the single most important risk factor associated with large vessel disease.

DOI: http://dx.doi.org/10.4038/sljch.v48i2.8705

${ }^{1}$ Department of Paediatrics, Bai Jerbai Wadia Hospital for Children, Mumbai, Maharashtra, India

*Correspondence: vaishnavi.iy@gmail.com

iD https://orcid.org/0000-0002-6455-1077

(Received on 01 June 2018; Accepted after revision on 20 July 2018)

The authors declare that there are no conflicts of interest Personal funding was used for the project.

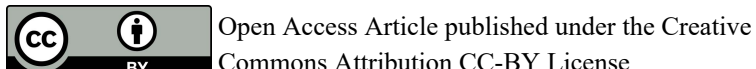
Copen Access Article published under the Creative Commons Attribution CC-BY License
(Keywords Atherosclerosis, carotid intima-media thickness, hypertension, ultrasonography)

\section{Introduction}

Atherosclerosis is a known cause of cardiovascular events in adults ${ }^{1}$. It often starts in childhood and is associated with hypertension, obesity, and dyslipidaemia. Children with chronic kidney disease (CKD) have in addition altered mineral metabolism, which contributes to an increased risk of cardiovascular disease $(\mathrm{CVD})^{2,3}$. The ensuing increased vascular stiffness and blood pressure (BP) also contribute to the increased frequency of hypertension and left ventricular hypertrophy in these children ${ }^{4}$. Early atherosclerotic changes include arterial wall stiffening and increased carotid intima-media thickness (CIMT), which can be reversed. An autopsy study of children with endstage renal disease (ESRD), demonstrated that soft tissue and vascular calcinosis were highly prevalent ${ }^{5}$. Ultrasonography of carotid arteries is an alternate, noninvasive method of studying cardiovascular disease in adults ${ }^{6,7,8}$. However, CIMT assessment is not yet recommended to screen children at higher cardiovascular risk ${ }^{9}$. There is not much data about CKD in Indian children. This prompted us to conduct a study on large vessel disease in children with $\mathrm{CKD}$ and evaluate the various comorbid factors.

\section{Objectives}

1. To evaluate early atherosclerotic changes using echocardiography and

2. To correlate with clinical and biochemical parameters associated with CKD.

\section{Method}

This cross sectional study was carried out in a tertiary care multispecialty hospital in Mumbai after obtaining informed consent from all parents of children with CKD. Ethical approval for study was obtained from the institutional Ethics Committee.

All 45 children diagnosed with CKD as per standard definition ${ }^{10}$ and registered in the nephrology unit were screened and 43 were selected for the study, 2 being excluded for having pre-existing cardiovascular disease. The selected patients were separated into 5 categories based on the stage of CKD as per standard terminology. The term end-stage renal disease (ESRD) was used for stage 5 children treated with dialysis or kidney transplantation ${ }^{10}$. This is shown in Table 1. 
Table 1: Standard terminology for stages of chronic kidney disease

\begin{tabular}{|c|c|c|}
\hline Stage & Description & GFR $\left(\mathrm{ml} / \mathrm{min} / 1.73 \mathrm{~m}^{2}\right)$ \\
\hline 1 & Renal damage with normal or increased GFR & $>90$ \\
\hline 2 & Renal damage with mild decrease in GFR & $60-89$ \\
\hline 3 & Moderate decrease in GFR & $30-59$ \\
\hline 4 & Severe decrease in GFR & $5-29$ \\
\hline 5 & Renal failure & $<15$ or on dialysis ${ }^{10}$ \\
\hline
\end{tabular}

GFR: Glomerular filtration rate

For estimation of kidney function the following formula was used. eGFR $=0.413 \times$ (height/Scr) if height is expressed in centimeters ${ }^{11}$. We studied their relative differences in occurrence of large vessel disease. The details were recorded in a case proforma designed for the study.

All patients included in the study group were assessed by complete history, physical examination and laboratory evaluation as per standard of care of the specialty clinic. The parameter studied was Bmode assessment of CIMT with a linear transducer of $12.0-\mathrm{MHz}$. The segments of common carotid artery $1-2 \mathrm{~cm}$ proximal to the bulb were scanned for noting the CIMT. The posterior (far) wall and the distance between the leading edges of the lumen-intima interface and the media-adventitia interface of the B-mode frame were considered to calculate $\mathrm{CIMT}^{12}$. (Figure I)

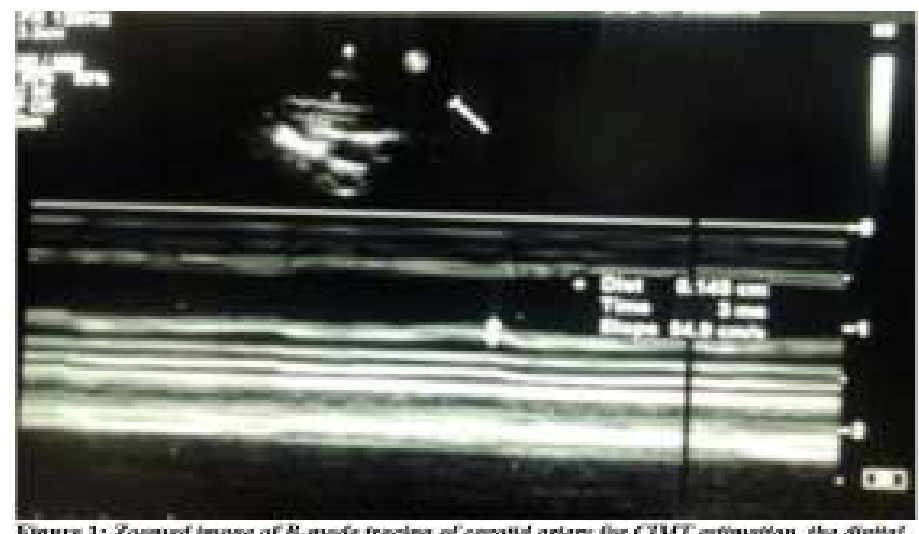

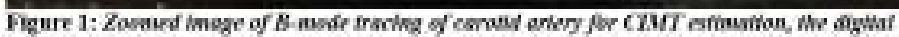

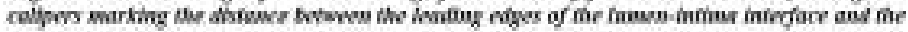

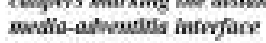

In the absence of data for normative cut-off of CIMT in Indians, a value of more than $0.08 \mathrm{~cm}$ was taken as abnormal. Although the threshold for abnormal CIMT in children is probably less than $0.08 \mathrm{~cm}$, in a study of 32 children with hypertension, $0.08 \mathrm{~cm}$ defined the high end of the range of values within this selected patient population $^{13}$. Details of treatment with antihypertensive drugs, iron supplements, erythropoietin injections, phosphate binders and calcium and vitamin D supplements were recorded in case proforma and analysed.

\section{Statistical analysis}

Continuous variables were expressed as means and standard deviations. Discrete variables were expressed as frequencies and percentages. Student's $t$-test was utilized in comparing the means of continuous normally distributed data. Chi-square test was used to test categorical data. Chi-square test for trends / FreemanHalton extension of the Fisher exact probability test (whichever was applicable) were used to assess categorical data related to the CKD classification.
All statistical tests were 2-tailed, and a $p$ value less than 0.05 was taken as statistically significant. Data were analysed using SPSS 13.0 software for Windows.

\section{Results}

A total of 43 children (35 males) with mean (SD) age of 8 (3.8) years diagnosed with CKD and satisfying the study criteria were included. The mean age of presentation was 4 years and 3 months with $34.8 \%$ in the age group 6-10 years. Mean duration of illness was 3.6 (SD 0.6) years. The mean eGFR was $23.22 \mathrm{ml} / \mathrm{min} / 1.73 \mathrm{~m}^{2}$. Eighty percent belonged to stage IV and $\mathrm{V}$ indicating late referral. Fifty five percent of children above 2 years were undernourished $(\mathrm{BMI}<5 \%)$. Reflux nephropathy followed by structural defects including hypoplasia, dysplasia and polycystic disease were the most common aetiological diagnoses. Of the 43, nine $(21 \%)$ had cardiovascular symptoms such as fatigue, dyspnoea and oedema. These cardiovascular symptoms had a positive predictive value of $88.9 \%$ for high CIMT (Table 2). 
Table 2: Positive predictive value of cardiac symptoms for underlying large vessel disease

\begin{tabular}{|l|c|c|c|}
\hline \multicolumn{1}{|c|}{ Data analysed } & High CIMT & Normal CIMT & Total \\
\hline Cardiac symptoms present & 8 & 1 & 34 \\
\hline Cardiac symptoms absent & 31 & 3 & 43 \\
\hline Total & 39 & 4 & 0.8889 \\
\hline Positive predictive value & \multicolumn{3}{|c|}{0.8205} \\
\hline Likelihood ratio & \multicolumn{3}{|c}{} \\
\hline
\end{tabular}

CIMT: carotid intima-media thickness

Of the 43 , twenty one were on antihypertensive drugs with $24 \%$ requiring more than one antihypertensive medication. Hypertension was noted in $8 / 43(18.6 \%)$ with systolic hypertension in $14 \%, 19 \%$ and $25 \%$ from stages III to $\mathrm{V}$ respectively indicating a linear increase with progression of CKD. Diastolic hypertension was noted in $12 \%$ of the cases in stages III \& IV and $25 \%$ in stage V. Despite therapy, $7 / 21$ had uncontrolled hypertension. Eighty percent of cases were on calcium channel blockers and $23 \%$ each on ACE inhibitors and centrally acting antihypertensive drugs, with almost $20 \%$ patients requiring more than one antihypertensive medication. Studying the prevalence of large vessel disease in CKD patients, 39/43 (90\%) of patients had high CIMT (Figure 2).

\section{CIMT in cm}

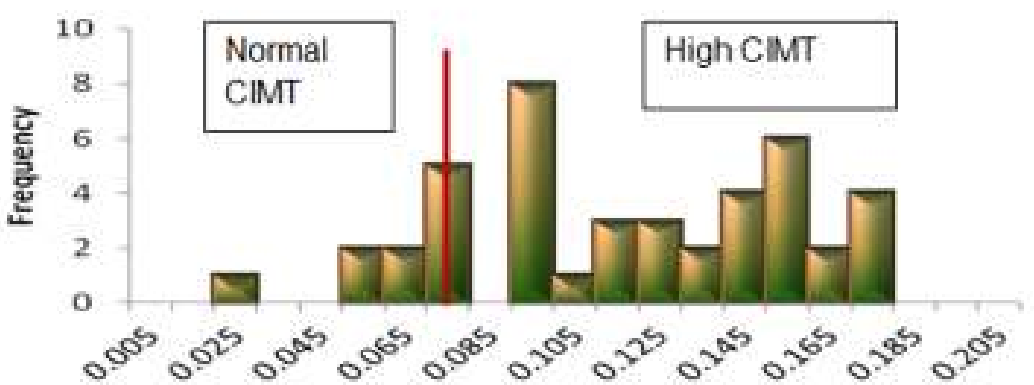

Figure 2: Frequency distribution of CIMT in $\mathrm{cm}$ in the study group CIMT: carotid intima-media thickness

There was no statistical difference between groups, with large vessel disease seen in all stages of CKD. However, the mean CIMT was significantly more in the ESRD group than in other stages $(0.139 \pm 0.009 \mathrm{~cm}$ vs $0.112 \pm 0.007 \mathrm{~cm})$ (Table 3$)$. There was a significant difference between the mean CIMT in normotensive patients $(0.104 \pm 0.008 \mathrm{~cm})$ and in well controlled systolic and diastolic hypertension $(0.134 \pm 0.009 \mathrm{~cm})$ and $(0.132 \pm 0.009 \mathrm{~cm})$ respectively. Mean CIMT in children with uncontrolled systolic and diastolic hypertension group $(0.152 \pm 0.009 \mathrm{~cm})$ was significantly ( $p=0.021)$ higher as compared to the mean CIMT in well controlled hypertensive and normotensive patients $(0.116 \pm 0.006 \mathrm{~cm})$. The mean CIMT did not differ significantly in the patients who had uncontrolled systolic and/or diastolic hypertension $(0.152 \pm 0.009 \mathrm{~cm})$ despite therapy and those with good control $(0.134 \pm 0.009 \mathrm{~cm})$ although the mean CIMT was lower in the latter group.
The study did not find any significant association between presence of anaemia, high calcium, high $\mathrm{Ca} \times \mathrm{P}$ product, hyperparathyroidism and proteinuria with CIMT (Table 3 ). The analysis also revealed that values of CIMT were higher in patients on continuous ambulatory peritoneal dialysis (CAPD) than without, indicating that large vessel disease is worse in patients on dialysis. No significant correlation was found between large vessel disease and anaemia, high calcium, high $\mathrm{Ca}$ $\mathrm{x} \mathrm{P}$ product, hyperparathyroidism, proteinuria, malnutrition, use of calcium containing phosphate binders. Of the 43 , twenty seven $(63 \%)$ had regular follow up in the outpatient department. One child with prolonged duration of illness and stage $\mathrm{V}$ CKD died during the study period. The laboratory evaluation revealed anaemia, hypocalcaemia and hyperparathyroidism. The child had a significantly high CIMT. 
Table 3: Association of variables with CIMT

\begin{tabular}{|c|c|c|c|}
\hline \multicolumn{2}{|r|}{ Variables } & \multicolumn{2}{|c|}{ CIMT } \\
\hline & & Mean values & $p$ value \\
\hline \multirow[t]{2}{*}{ Age of presentation } & $<1$ year & 0.1146 & \multirow[b]{2}{*}{0.4260} \\
\hline & $>1$ year & 0.1252 & \\
\hline \multirow[t]{2}{*}{ End stage renal disease } & Yes & 0.1393 & \multirow[b]{2}{*}{0.0326} \\
\hline & No & 0.1127 & \\
\hline \multirow[t]{2}{*}{ Stage } & Stage $2+3$ & 0.1211 & \multirow[b]{2}{*}{0.9419} \\
\hline & Stage $4+5$ & 0.1222 & \\
\hline \multirow[t]{2}{*}{ Malnutrition } & Yes & 0.1200 & \multirow[b]{2}{*}{0.2847} \\
\hline & No & 0.1331 & \\
\hline \multirow[t]{6}{*}{ Systolic hypertension } & Uncontrolled systolic hypertension & 0.1529 & \multirow[b]{2}{*}{0.0214} \\
\hline & No uncontrolled systolic hypertension & 0.1160 & \\
\hline & Uncontrolled systolic hypertension & 0.1529 & \multirow[b]{2}{*}{0.2486} \\
\hline & Controlled systolic hypertension & 0.1346 & \\
\hline & Controlled systolic hypertension & 0.1346 & \multirow[t]{2}{*}{0.0192} \\
\hline & No systolic hypertension & 0.1041 & \\
\hline \multirow[t]{6}{*}{ Diastolic hypertension } & Uncontrolled diastolic hypertension & 0.1528 & \multirow[b]{2}{*}{0.0214} \\
\hline & No uncontrolled diastolic hypertension & 0.1160 & \\
\hline & Uncontrolled diastolic hypertension & 0.1529 & \multirow[b]{2}{*}{0.1904} \\
\hline & Controlled diastolic hypertension & 0.1323 & \\
\hline & Controlled diastolic hypertension & 0.1323 & \multirow[b]{2}{*}{$\mathbf{0 . 0 3 0 7}$} \\
\hline & No diastolic hypertension & 0.1043 & \\
\hline \multirow[t]{2}{*}{ Anaemia } & Yes & 0.1265 & \multirow[b]{2}{*}{0.1724} \\
\hline & No & 0.1070 & \\
\hline \multirow[t]{2}{*}{ Hypercalcaemia } & Yes & 0.1150 & \multirow[b]{2}{*}{0.8009} \\
\hline & No & 0.1223 & \\
\hline \multirow[t]{2}{*}{ Hypocalcaemia } & Yes & 0.1222 & \\
\hline & No & 0.1216 & 0.9584 \\
\hline Hyperphosphataemia & Yes & 0.1238 & \\
\hline & No & 0.1213 & 0.8567 \\
\hline High calcium & Yes & 0.1181 & \\
\hline phosphorus product & No & 0.1237 & 0.6741 \\
\hline Hyperparathyroidism & Yes & 0.1213 & \\
\hline & No & 0.1231 & 0.8850 \\
\hline Proteinuria & Yes & 0.1192 & \\
\hline & No & 0.1292 & 0.4627 \\
\hline Vitamin D3 & Yes & 0.1086 & \\
\hline supplements & No & 0.1246 & 0.3306 \\
\hline Antihypertensive use & Yes & 0.1407 & \\
\hline & No & 0.1041 & 0.0014 \\
\hline Alfa calcidol use & Yes & 0.1085 & \\
\hline & No & 0.1278 & 0.1401 \\
\hline Calcium containing & Yes & 0.1288 & \\
\hline phosphate binder use & No & 0.1125 & 0.1835 \\
\hline Continuous ambulatory & Yes & 0.1440 & \\
\hline peritoneal dialysis & No & 0.1370 & 0.7456 \\
\hline Follow up & Irregular & 0.1297 & \\
\hline & regular & 0.1174 & 0.3286 \\
\hline
\end{tabular}

\section{Discussion}

Large vessel disease occurs very early in CKD children $^{14,15}$. Studies of young adults developing ESRD while still children found an increased frequency of abnormal CIMT, diminished arterial wall compliance and coronary artery calcification which are considered markers of asymptomatic atherosclerosis and predictors of future symptomatic $\mathrm{CVD}^{15-17}$. Ninety percent of the patients in the study had high CIMT including children in earlier stages, suggestive of large vessel disease being universal in CKD patients which is similar to other studies on the same subject ${ }^{18}$. However, only 9/43 (21\%) had cardiovascular symptoms. Amongst the symptomatic patients $(n=9)$ fatigue was seen in $66.6 \%$, dyspnoea in $55 \%$ 
and oedema in $22 \%$. However, the presence of any of the above symptoms has a positive predictive value of $88.9 \%$ for high CIMT (Table 2). We did not find any studies which analysed these parameters. Thus large vessel disease in CKD remains predominantly subclinical. When ESRD group was studied separately the mean CIMT was significantly higher than in other stages. This finding is also supported by Milliner et al. based on necropsy findings in children with $\mathrm{ESRD}^{5}$.

Children with uncontrolled systolic / diastolic hypertension had significantly higher mean CIMTs as compared to others. What was more astounding was the fact that the mean CIMT did not differ significantly in patients who had uncontrolled systolic/diastolic hypertension despite therapy and those with good control, although the mean CIMT was lower in the latter group. Children who were normotensive had significantly lower mean CIMT than those who were normotensive on antihypertensive drugs. The above findings indicate that systolic or diastolic hypertension contributes to large vessel disease which might not revert completely even with good control of BP. Hence, children who are on antihypertensive medication to maintain a particular BP for that age, still have a higher cardiovascular risk in comparison to children with the same BP without using antihypertensive drugs. The difference may also be due to a delay between a faster control of BP with antihypertensive drugs versus a slower effect on the large vessel disease. A cross-sectional CIMT analysis after one year follow-up of 101 children 2-18 years old with mild to moderate CKD found CIMT to be significantly increased among children with CKD, along with prevalence of other cardiovascular risk factors, among which hypertension and dyslipidemia are significantly associated with raised CIMT $^{19}$. Various studies have found greater arterial stiffness and demonstrated that systolic hypertension was the chief determinant of abnormal arterial wall compliance $^{20-22}$.

Based on previous studies ${ }^{23,24}$, we expected to find a correlation between high CIMT and abnormal calcium phosphorus metabolism, but there was no such association found. This can be due to the fact that many children had normal levels of serum calcium and phosphorus. Only $30 \%$ of children had an average serum phosphorus value that was above the published Kidney Disease Outcomes Quality Initiative cut-offs for medical therapy ${ }^{25}$.This could be due to the fact that almost $58 \%$ were on calcium containing phosphorus binders. Only 3 children had an elevated calcium-phosphorus product, lending further proof to this hypothesis. The study found no significant association between CIMT and anaemia, hyperparathyroidism, or proteinuria.
This study has some limitations. The cross sectional nature of the study limits the ability to infer causality. The small sample size limits the generalizability of the study.

\section{Conclusions}

CIMT is an important echocardiographic marker for cardiovascular disease in CKD. Hypertension is the single most important risk factor associated with large vessel disease.

\section{Acknowledgement}

We thank Dr. Y. K. Amdekar, director of B. J. Wadia Hospital for Children, Mumbai for allowing us to conduct the study.

\section{References}

1. Labarthe DR, Atherosclerosis. In: Colilla J, Gaithersburg, MD, editors. Epidemiology and prevention of cardiovascular diseases: A global challenge. Aspen Publishers; 1998. p. 29-41.

2. Berenson GS, Srinivasan SR, Bao W, Newman WP 3rd, Tracy RE, Wattigney W. Association between multiple cardiovascular risk factors and atherosclerosis in children and young adults. The Bogalusa Heart Study. New England Journal of Medicine 1998; 338:16506.

https://doi.org/10.1056/NEJM1998060433823 02

PMid: 9614255

3. McGill HC Jr., McMahan CA, Zieske AW, Sloop GD, Walcott JV, Troxclair DA, et al. The patho-biological determinants of atherosclerosis in youth (PDAY) research group: Associations of coronary heart disease risk factors with the intermediate lesion of atherosclerosis in youth. Arteriosclerosis, Thrombosis and Vascular Biology 2000; 20(8):1998-2004.

https://doi.org/10.1161/01.ATV.20.8.1998

4. Mitsnefes MM: Cardiovascular disease in children with chronic kidney disease. Journal of the American Society of Nephrology 2012; 23: $578-85$.

https://doi.org/10.1681/ASN.2011111115

PMid: 22383696 PMCid: PMC331251

5. Milliner DS, Zinsmeister AR, Lieberman E, Landing B. Soft tissue calcification in paediatric patients with end-stage renal disease. Kidney International 1990; 38:931-6. https://doi.org/10.1038/ki.1990.293 PMid: 2266678 
6. Salonen JT, Salonen R (1991). Ultrasonographically assessed carotid morphology and the risk of coronary heart disease. Arteriosclerosis, Thrombosis and Vascular Biology 1991; 11(5):1245-9. https://doi.org/10.1161/01.ATV.11.5.1245

7. Heiss G, Sharrett AR, Bames R, Chambless LE, Szklo M, Alzola C. Carotid atherosclerosis measured by B Mode ultrasound in populations: Associations with cardiovascular risk factors in the ARIC study. American Journal of Epidemiology 1991; 134(3):250-6. https://doi.org/10.1093/oxfordjournals.aje.a116 078

PMid: 1877584

8. Cobble M, Bale B. Caroitd intima media thickness: knowledge and application to everyday practice. Postgraduate Medical Journal 2010; 122(1):10-18. https://doi.org/10.3810/pgm.2010.01.2091

PMid: 20107284

9. National high blood pressure education program working group on high blood pressure in children and adolescents: The fourth report on the diagnosis, evaluation, and treatment of high blood pressure in children and adolescents. Pediatrics 2004; 114[Suppl. 4th report]: 555-76.

10. National Kidney Foundation K/DOQI clinical practice guidelines for chronic kidney disease: evaluation, classification, and stratification. American Journal of Kidney Disease 2002; 39(1):S1-266.

PMid: 11904577

11. Schwartz GJ, Munoz A, Schneider MF, et al. New equations to estimate GFR in children with CKD. Journal of the American Society of Nephrology 2009; 20: 629-37. https://doi.org/10.1681/ASN.2008030287 PMid: 19158356 PMCid: PMC2653687

12. Touboul P-J, Hennerici MG, Meairs S, Adams $\mathrm{H}$, Amarenco P, Bornstein N, et al. Mannheim carotid intima-media thickness consensus (2004-2006). An update on behalf of the Advisory Board of the 3rd and 4th Watching the Risk Symposium, 13th and 15th European Stroke Conferences, Mannheim, Germany, 2004, and Brussels, Belgium, 2006. Cerebrovascular Diseases 2007; 23(1):75-80. https://doi.org/10.1681/ASN.2008030287 PMid: 19158356 PMCid: PMC2653687

13. Sorof JM, Alexandrov AV, Cardwell G, Portman RJ. Carotid artery intimal medial thickness and left ventricular hypertrophy in children with elevated blood pressure. Pediatrics 2003; 111(1):61-6. https://doi.org/10.1542/peds.111.1.61 PMid: 12509555

14. Oh J, Wunsch R, Turzer M, et al. Advanced coronary and carotid arteriopathy in young adults with childhood-onset chronic renal failure. Circulation 2002; 106: 100-10.

https://doi.org/10.1161/01.CIR.0000020222.63 035.C0

PMid: 12093777

15. Groothoff JW, Gruppen MP, Offringa M, et al. Increased arterial stiffness in young adults with end-stage renal disease since childhood. Journal of the American Society of Nephrology 2002; 13: 2953-61.

https://doi.org/10.1097/01.ASN.0000037677.1 6961.DF

PMid: 12444214

16. London GM, Guerin AP, Marchais SJ, Metivier F, Pannier B, Adda H. Arterial media calcification in end-stage renal disease: impact on all-cause and cardiovascular mortality. Nephrology Dialysis Transplantation 2003; 18:1731-40.

https://doi.org/10.1093/ndt/gfg414

17. Blacher J, Pannier B, Guerin AP, Marchais SJ, Safar ME, London GM. Carotid arterial stiffness as a predictor of cardiovascular and all-cause mortality in end-stage renal disease. Hypertension 1998; 32:570-4.

https://doi.org/10.1161/01.HYP.32.3.570

PMid: 9740628

18. Civilibal M. Oflaz H. Traditional and "new" cardiovascular risk markers and factors in paediatric dialysis patients. Pediatric Nephrology 2007; 22(7): 1021-9.

https://doi.org/10.1007/s00467-007-0451-0

PMid: 17340147

19. Brady TM, Schneider MF, Flynn JT, Cox C, Samuels J, Saland J, et al. Carotid intimamedia thickness in children with CKD: Results from the CKiD Study. Clinical Journal of the American Society of Nephrology 2012; 7(12): 1930-7.

https://doi.org/10.2215/CJN.03130312

PMid: 22977209 PMCid: PMC3513743

20. de Simone G, Daniels SR, Devereux RB, Meyer RA, Roman MJ, de Divitiis O, et al. Left ventricular mass and body size in normotensive children and adults: Assessment of allometric relations and impact of 
overweight. Journal of the American College of Cardiology 1992; 20: 1251-60.

https://doi.org/10.1016/0735-1097(92)90385-Z

21. London GM: Large arteries haemodynamics: conduit versus cushioning function. Blood Pressure Supplement 1997; 2: 48-51.

PMid: 9495627

22. Litwin M. Wuhl E, Jourdan C, Trelewicz J, Niemirska A, Fahr $\mathrm{K}$ et al. Altered morphologic properties of large arteries in children with chronic renal failure and after renal transplantation. Journal of the American Society of Nephrology 2005; 16:1494-500, https://doi.org/10.1681/ASN.2004110932 PMid: 15772249

23. Mitsnefes MM, Kimball TR, Kartal J, Witt SA, Glascock BJ, Khoury PR, et al. Cardiac and vascular adaptation in paediatric patients with chronic kidney disease: Role of calciumphosphorus metabolism. Journal of the American Society of Nephrology 2005; 16:2796-803.

https://doi.org/10.1681/ASN.2005030291

PMid: 16049067
24. Chen NX, O'Neill KD, Duan D, Moe SM: Phosphorus and uremic serum up-regulate osteopontin expression in vascular smooth muscle cells. Kidney International 2002; 62: 1724-31. https://doi.org/10.1046/j.15231755.2002.0062 5.X

PMid: 12371973

25. National Kidney Foundation: K/DOQI clinical practice guidelines for bone metabolism and disease in children with chronic kidney disease. American Journal of Kidney Disease 2005; 46(1): 1-122.

PMid: 15983951 